\title{
Muito além dos muros
}

\author{
Jéssica Patrícia Cavalheiro*, Fernanda Lopez Rosell** e Aylton Valsecki Júnior***. \\ * Graduação na Faculdade de Odontologia de Araraquara- UNESP. \\ ** Professor Assistente Doutor - Departamento de Odontologia Social - \\ Faculdade de Odontologia de Araraquara- UNESP. \\ *** Professor Adjunto - Departamento de Odontologia Social -Faculdade de \\ Odontologia de Araraquara- UNESP.
}

\section{RESUMO}

A arte de lidar com o semelhante vai além do simples contato de um prestador de serviços para o recebedor do serviço, afinal a boca é apenas uma parte do indivíduo. $\mathrm{O}$ projeto do PET- SAÚDE proporciona ao acadêmico a experiência de desbravar o mundo além dos muros da faculdade, o que é simplesmente sensacional. Essa é a melhor maneira de formar o profissional de odontologia, com uma visão humanista, crítica e reflexiva. Propiciando ao aluno a oportunidade de deparar-se com a realidade dos postos públicos e desenvolver as competências gerais do cirurgião-dentista, como a comunicação com outros profissionais, vivenciando a multiprofissionalidade, interdisciplinaridade e transdisciplinaridade, importantes na promoção da saúde. Durante as visitas aos municípios foram executadas as atividades de atenção à saúde com ações de prevenção e de reabilitação. Mesmo diante de um cenário de carência de recursos, a falta de determinados materiais, comuns na clínica diária, não impossibilitou a realização dos procedimentos e do cuidar. Esta experiência é imprescindível, pois auxilia na tomada de decisões e estabelecimento da relação custo- efetividade na carreira profissional, baseada não só em evidências científicas, mas também nas necessidades de uma determinada população. Portanto, a experiência de participar do PET, permite a formação completa do acadêmico, pautada também nas Ciências Humanas e Sociais. Dessa forma, ir além dos muros da faculdade proporciona uma visão completa e humana do paciente, que não se restringe mais a apenas uma "parte" doente, por poder ter seu contexto compreendido e integrado na visão de cada petiano.

Descritores: Saúde holística; atenção primária à saúde; educação em odontologia.

\section{INTRODUÇÃO}

A expansão e a qualificação da atenção básica, organizada pela estratégia Saúde da Família, é compreendida como estratégia de reorientação do modelo assistencial, compondo o conjunto de prioridades políticas apresentadas pelo MS e aprovadas pelo Conselho Nacional de Saúde. Mediante a adstrição de clientela, as equipes Saúde da Família estabelecem vínculo com a população, possibilitando o compromisso e a corresponsabilidade destes profissionais com os usuários e comunidade. Neste sentido, as diretrizes da Política Nacional de Saúde Bucal apontam para 
uma reorganização da atenção em saúde bucal em todos os níveis de atenção.

As Diretrizes Curriculares Nacionais (DCN) para o curso da graduação em odontologia foram instituídas por meio de uma resolução do Conselho Nacional de Educação em conjunto com a Câmara de Educação Superior e homologada pelo ministro da educação em 4 de dezembro de 2001 através da Resolução CNE/CES n ${ }^{\circ} .3$ de 19 de fevereiro de $2002^{6}$.

A proposta do PET - Saúde é realizada em parceria com a Faculdade de Odontologia e a Faculdade de Ciências Farmacêuticas do Campus de Araraquara. O objetivo é a inserção dos acadêmicos de Odontologia e de Ciências Farmacêuticas junto ao serviço público de saúde e, por consequência, alinhar a formação profissional a realidade, fazendo com que o acadêmico vivencia na prática as Diretrizes Curriculares Nacionais.

Assim sendo, promover o desenvolvimento de atributos, por meio do aprendizado teórico-prático, possibilita aos acadêmicos o exercício profissional com qualidade nas áreas de cuidado integral à saúde individual, de comunidades e na gestão e organização do trabalho na Estratégia de Saúde da Família.

A consolidação dessa estratégia requer sustentação por um processo de substituição da rede básica de serviços tradicionais, que ainda hoje são centradas na doença e no curativismo, pela promoção, prevenção, recuperação e reabilitação da saúde. Este trabalho realizado em parceria IES/serviços de saúde pode qualificar os profissionais do serviço, assim como, contribuir para uma formação acadêmica de acordo com o contexto do SUS.Caracterizando-se como instrumento para qualificação em serviço dos profissionais da saúde, bem como de iniciação ao trabalho e vivências dirigidos aos estudantes das graduações em saúde, de acordo com as necessidades do SUS. ${ }^{8}$

Este projeto de extensão vai além das diretrizes da graduação buscando uma interação do mundo universitário com os problemas de saúde pública. Visando a integração entre faculdade-munícipios e população, por meio de: levantamentos epidemiológicos, territorialização e real conhecimento dos problemas locais (desde a saúde em si até problemas de infraestrutura municipal que de alguma forma intervenha direta ou indiretamente na saúde pública), ações resolutivas e interceptativas de saúde, ações educativas e preventivas. Os profissionais devem desenvolver habilidades e competências gerais que ultrapassem os limites do conhecimento técnico, algumas delas são: comunicação, liderança, atuação de maneira colaborativa/em equipe, tomada de decisões, educação permanente ${ }^{8}$.

O objetivo desse trabalho é relatar a experiência de participar do programa PRÓ-PET-Saúde e quais as competências gerais da Diretrizes Curriculares Nacionais para o curso de Odontologia (DCN) foram desenvolvidas e o impacto no formação profissional.

\section{MATERIAIS E MÉTODOS}

O PET Saúde- Atenção Básica realiza atividades com caráter multidisciplinar em 6 municípios do DSR- III: Motuca, Dobrada, Dourado, Rincão, Gavião Peixoto e Trabiju localizados próximo à cidade de Araraquara, que estão inseridos nesta Regional de Saúde e foram escolhidos por terem até 15.000 habitantes, geralmente uma população que tem maior risco e vulnerabilidade à saúde. Os 12 acadêmicos participantes deste PET faziam um rodízio semanal, onde cada dupla visitava semanalmente os municípios. 
A meta geral do Projeto é promover a saúde bucal na rede básica de atenção a partir de estratégias da atenção básica odontológica, com a inserção de estudantes de odontologia. E as metas específicas são:

- Capacitação profissional das equipes de saúde em ações de atenção básica odontológica;

- Conhecimento epidemiológico de enfermidades bucais com prescrição territorial;

- Ordenação de ações preventivas e curativas segundo referenciais de risco e vulnerabilidades;

- Instrumentalização profissional no uso tecnologias leves e duras para a atenção básica (estágios de resolubilidade);

- Utilização racional dos insumos odontológicos;

- Promover o desenvolvimento de habilidades e competências que possibilitem aos estudantes o exercício profissional com qualidade nas áreas de cuidado integral e humanizado à saúde individual, de comunidades e na gestão e organização do trabalho na ESF;

- Confeccionar material de apoio para usuários e profissionais, considerando as necessidades demandadas;

- Prestação de assistência na ordenação de demandas gerais e específicas;

- Realização de pesquisas que contribuam para a melhoria da atenção básica odontológica.

Para conseguir abranger ao máximo as metas estipulas foi elaborado pelos preceptores e docentes da Faculdade cronograma das atividades, essas foram divididas no período de dois anos para execução:

- $\mathbf{1}^{\mathbf{o}}$ ano. Conhecimento da territorialização dos municípios/unidades de saúde, gestores e equipes de trabalho/Grupos de discussão e estudo com encontros regulares pré-agendados/Análise situacional. Planejamento do Trabalho, elaboração de instrumentos de ação gerencial/Capacitações/Ações educativas de promoção e prevenção. Relatórios. Análises do flúor na água da rede de abastecimento público.

- $\mathbf{2}^{\mathbf{0}}$ ano. Trabalho/Intervenções propostas e Pesquisas Dirigidas. Relatórios e divulgação dos resultados. Análises do flúor na água da rede de abastecimento público.

Periodicamente são feitas reuniões com os tutores, preceptores e acadêmicos a fim de traçar metas para as visitas e apresentar os problemas vivenciados e discutir suas possibilidades de resolução. Isso permite a troca de conteúdo científico e experiências pessoais/profissionais, tendo diferentes olhares para um mesmo problema.

Os alunos têm a reponsabilidade de:

- Participar como observador e capacitador em atividades de grupos de educação em saúde, visitas domiciliares, ações de promoção e prevenção, reuniões de equipe, acolhimento, capacitação da equipe em saúde bucal, além de realizar atendimento odontológico supervisionado, na filosofia do trabalho em equipe das USF integrantes desta proposta.

- Participar de reuniões semanais para planejamento de atividades. Realizar leituras pertinentes ao tema.

- Elaborar materiais de apoio para usuários e profissionais;

- Elaborar artigos científicos e relatórios;

- Participar de eventos científicos.

Os preceptores são responsáveis por:

- Receber, supervisionar e orientar aos alunos nas atividades propostas;

- Participar de planejamento e avaliação das atividades;

Revista da ABENO • 13(2): 82-87, 2013 
- Realizar intervenções educativas, treinamentos, capacitações ou cursos solicitados pelo tutor.

A proposta do PET inclui também a realização de um Projeto de Pesquisa, no qual cada dupla, juntamente com seus preceptores definem a temática e executa a pesquisa com base em algum problema vivenciado durante as visitas ou diagnóstico da situação. Isso permite que as pesquisas contribuam também para a qualificação do serviço, além do aprendizado ao acadêmico.

\section{RESULTADOS}

A participação no PET- Atenção proporcionou ao acadêmico desenvolver na prática algumas das competências gerais e específicas presentes nas Diretrizes Nacionais para o Curso de Odontologia, como:

- Atenção à saúde: por meio de atividades de promoção e prevenção em saúde;

- Análise do custo- efetividade de materiais conforme a situação financeira de cada município;

- Interação com as pessoas de diversas áreas, como enfermeiros, médicos, psicólogos.

- Liderança, principalmente em questões que envolvem a tomada de decisões;

- Educação permanente, por meio do aprendizado contínuo que o Projeto ofereceu, através de palestras, congressos, e as reuniões semanais com preceptores, tutores e petianos.

- Visão ampliada da Odontologia com base nas Ciências Sociais e Humanas.

- Inserção do acadêmico na área da pesquisa científica, em virtude da proposta de execução de um Projeto de Pesquisa.

Além dos resultados abordados acima, o acadêmico teve a oportunidade de entender na teoria e na prática significado e importância do processo de territoriali- zação, para assim poder executar atividades específicas para o perfil de um determinado município.

Dessa forma, o envolvimento da IES com o serviço possibilitou uma qualificação da atenção básica, garantindo qualidade e resolutividade dos casos. Além da garantia de uma atenção básica articulada com toda a rede de serviços, assegurando a integralidade nas ações de saúde bucal e o impacto das ações de saúde bucal por meio de indicadores adequados. Portanto, qualificou os profissionais e a formação dos estudantes.

\section{DISCUSSÃO}

A proposta do PET em parceria com o Ministério da Educação possibilita estratégias que favorecem a aproximação das instituições de ensino e dos serviços de saúde e uma formação dos acadêmicos pautada pelas necessidades reais da população ${ }^{5}$.

É necessário conhecer o território que constitui a área de abrangência da Unidade de Saúde (US) para identificar como vivem, adoecem e morrem as pessoas. Assim, esta estratégia de ação em saúde se contrapõe às propostas de criação de programas de atenção à saúde que são aplicados, indistintamente, em todo o território nacional, que não levam em conta as especificidades de cada população. Este modelo na Saúde Coletiva foi adotado por muitos anos e não gerou mudanças na assistência à saúde que dessem conta das questões que o setor deveria enfrentar (ALMEIDA, 2007) ${ }^{1}$.

Nesse contexto se torna vital traçar o perfil da população que será contemplada pelo projeto, compreendendo a relação do indivíduo e do coletivo diante do território, das condições políticas, econômicas e sociais e sua influência na saúde. Segundo Barcellos et., 2002, ${ }^{3}$ o território é o resultado de uma acumulação de situações históricas, ambientais, sociais que promovem 
condições particulares para a produção de doenças.

A participação no PET aproxima ainda mais o acadêmico das competências gerais e específicas presentes nas Diretrizes Curriculares Nacionais (DCN) para o curso da graduação em odontologia ${ }^{6}$.

As atividades de promoção da saúde bucal promoveram a compreensão a partir da observação dos trabalhadores e a criação do vínculo e acolhimento com os pacientes, por meio da visão holística. Estas experiências aproximaram a teoria da prática "Os profissionais de saúde, dentro de seu âmbito profissional, devem estar aptos a desenvolver ações de prevenção, promoção, proteção e reabilitação da saúde, tanto em nivel individual quanto coletivo. Cada profissional deve assegurar que sua prática seja realizada de forma integrada e contínua com as demais instâncias do sistema de saúde, sendo capaz de pensar criticamente, de analisar os problemas da sociedade e de procurar soluções para os mesmos. Os profissionais devem realizar seus serviços dentro dos mais altos padrões de qualidade e dos princípios da ética/bioética, tendo em conta que a responsabilidade da atenção à saúde não se encerra com o ato técnico, mas sim, com a resolução do problema de saúde, tanto em nível individual como coletivo." "(Resolução CES/CNE $n^{\circ} 03$ DCN/Odontologia).

Um aspecto fundamental é a tomada de decisão, pois possibilitou a habilidade de avaliar e decidir a conduta mais apropriada em uma determinada situação. Segundo Bazerman (2004; p. 06), a tomada de decisão" "é baseado em um conjunto de premissas que determinam como uma decisão deve ser tomada e não como a decisão é tomada"..

Assim sendo, a participação aluno no PET - Saúde durante a graduação fez com que cada paciente fosse visto como um ser humano que vem repleto de histórias, costumes, medos, expectativas e crenças, e não apenas, uma pessoa que tem um dente para ser restaurado. Colocar-se no lugar do outro tornou-se fundamental para nortear o atendimento de cada paciente de forma individualizada, respeitando o modo de cada pessoa pensar e agir. "a tendência para sentir o que se sentiria caso se estivesse na situação e circunstâncias experimentadas por outra pessoa" 7

\section{CONCLUSÕES}

Portanto, ao participar do PET- Saúde os acadêmicos tiveram a oportunidade de desvendar o mundo que existe além dos muros da faculdade e de todo o "protecionismo" que circunda o estudante. Assim sendo, vivenciaram na prática o acadêmico das Diretrizes Curriculares Nacionais (DCN) do curso de Odontologia, auxiliando no desenvolvimento das Competências Gerais para formação do profissional.

Desta forma, ir além dos muros da faculdade proporcionou uma visão completa e humana do paciente, que não se restringe mais a apenas uma "parte" doente, por poder ter seu contexto compreendido e integrado pelos futuros profissionais da área da saúde.

\section{REFERÊNCIAS}

1. Almeida, et al. 2007. Territorialização em Saúde. Revista Eletrônica da Associação dos Geógrafos Brasileiros - Seção Três Lagoas Três Lagoas - MS, V 1 n. ${ }^{\circ} 6$-ano 4, Novembro de 2007.

2. Bazerman, M.H. Processo Decisório: para cursos de Administração, Economia e MBAs. Rio de Janeiro: Elsevier Editora, 2004.

3. Barcellos, C.; Sabroza, P.C.; Peiter, P.; 
Rojas, L.I. (2002) Organização espacial, saúde e qualidade de vida: A análise espacial e o uso de indicadores na avaliação de situações de saúde. Informe Epidemiológico do SUS, 11(3): 129-138

4. Brasil. Ministério da Educação. Resolução $n^{\circ}$ CNE/CES 3/2002 de 06 de novembro de 2001. Institui as Diretrizes Curriculares Nacionais dos Cursos de Farmácia e Odontologia. Diário Oficial, Brasília, 04 de março de 2002, seção 1, p.10.

5. Brasil. Ministério da Saúde. Ministério da Educação.Programa Nacional de Reorientação da Formação Profissional em Saúde - Pró-Saúde : objetivos, implementação e desenvolvimento potencial / Ministério da Saúde, Ministério da Educação. - Brasília: Ministério da Saúde [Internet]. 2007 [citado em 6 out 2013]. Disponível em: http://prosaude.org/publicacoes/pro_saud e1.pdf.

6. Conrado CA, Gomes GS, Robazza CRC. O projeto pedagógico: estruturação e desenvolvimento curriculares - o currículo multidisciplinar integrado. In: Terada RSS, Nakama L. A implantação das Diretrizes Curriculares Nacionais de Odontologia: a experiência de Maringá. São Paulo: Hucitec; 2004. p. 86-112.

7. Ferreira, A. B. H. Novo Dicionário Língua Portuguesa. Rio de Janeiro. Nova Fronteira, 1980.

8. Resolução CNE/CES 4/2001, de 7 de novembro de 2001. Institui Diretrizes Curriculares Nacionais do Curso de Graduação em Medicina. Disponível em: http://portal.mec.gov.br/cne/arquivos/pdf /CES04.pdf. Acesso em: 15 de fevereiro de 2014.

\section{ABSTRACT Beyond the walls}

The art of dealing with the similar goes beyond simply contact a service provider to the recipient of the service, after the mouth is only part of the individual. The design PET - Saúde provides the academic experience of exploring the world beyond the walls of the college, which is simply phenomenal. This is the best way to form the dental professional with a humanist, critical and reflective view. Providing students the opportunity to encounter the reality of payphones and develop the general skills of the dentist, as communication with other professionals, experiencing multiprofessionality and transdisciplinarity, important in health promotion. During visits to municipalities were executed activities of health care with prevention and rehabilitation . Even against a background of lack of resources, lack of certain materials, common clinical presentation not prevented the carrying out of procedures and care. This experience is essential because it helps in decision making and establishment of costeffectiveness in their professional careers, based not only on scientific evidence, but also the needs of a given population. Therefore, the experience of participating in the PET allows the complete formation of the academic , also marked the Humanities and Social Sciences. Therefore, going beyond the walls of the college provides a comprehensive and humane view of the patient, which is no longer restricted to just one sick " part ", because it may have its context understood and integrated into the vision of each petiano .

Descriptors: Holistic, health care, dentistry. 